\begin{tabular}{|c|l|}
\hline Title & $\begin{array}{l}\text { An overview of the Web of Science record of scientific publications (2004-2013) from Nepal: focus on disciplinary } \\
\text { diversity and international collaboration }\end{array}$ \\
\hline Author(s) & Gautam, Pitambar \\
\hline Citation & $\begin{array}{l}\text { Scientometrics, 113/3), 1245-1267 } \\
\text { https://doi.org/10.1007/S11192-017-2538-0 }\end{array}$ \\
\hline Issue Date & 2017-12 \\
\hline Doc URL & http:/hdl.handle.net/2115/70409 \\
\hline Type & article(author version) \\
\hline File Information & Gautam_SCIM_2017accepvers.pdf \\
\hline
\end{tabular}

Instructions for use 


\title{
An Overview of the Web of Science Record of Scientific Publications (2004- 2013) from Nepal: Focus on Disciplinary Diversity and International Collaboration
}

\author{
Pitambar Gautam \\ Creative Research Institution (CRIS), Hokkaido University, N21 W10, Kita-ku, Sapporo, Hokkaido 001-0021, \\ Japan. E-mail: pgautam@cris.hokudai.ac.jp
}

\begin{abstract}
This study attempts to use bibliometry as a tool for exploration of the passage of development of the science and technology through analysis of the scientific publications from a developing country by taking into account its state of higher education and the unique political, economic and geo-bioenvironmental conditions. It deals with Nepal considering its scientific output during 1966-2016 reflected as publications indexed in the Web of Science Database. Preliminary examination of the publication record for Nepal reveals a number of the following characteristics: i) low volume, negligible growth and lack of distinct trend until 1989; ii) a marked growth followed by stagnation linked to political instability during the next 15 years; and (iii) recovery and accelerated growth thereafter. Research publications during 2004-2013 increased thrice compared to 1994-2003, with expansion and shifts in disciplinary profile expressed in Essential Science Indicators 22 fields.
\end{abstract}

Detailed bibliometric analysis of the 2004-2013 publications (3,011 articles and reviews) from Nepal suggests the citation impact of about the world average, but very high $(76 \%)$ average international coauthorship. The disciplinary profile is diverse judging from seven most productive fields (clinical medicine, plant \& animal science, environment/ecology, geosciences, agricultural sciences, and chemistry) with $4-40 \%$ national disciplinary share. Clinical medicine, geosciences and agricultural sciences exhibit relatively high impact. Fields with the smaller share $(<3 \%)$, such as molecular biology $\&$ genetics, economics \& business, psychiatry \& psychology, materials science, and biology \& biochemistry, exhibit citation impact distinctly higher than the world average. Publications from Nepal show the presence of a vast international collaborative network that is dominated by authors affiliated to institutions in the USA, India, UK, Japan, South Korea and Germany.

Based on the analysis of the disciplinary diversity and the national versus global relative disciplinary shares, Nepal's publication profile is inferred to be a hybrid of the 'bio-environmental' and 'western' models. Concerning the state of the development of science and technology in Nepal during 2004-2013, the high dependence on international collaboration in the internationally visible publications in most of the bio-environmental, physico-chemical and engineering fields points to basically a 'building-up stage'. In clinical medicine (with a large share of public health) and geosciences, however, Nepal has demonstrated research strengths evident from the high citation impact in these fields. Moreover, the available data suggest that significant advances were made in higher education sector in both fields during the last 25 years. Despite the notable negative effect of the prolonged domestic armed political conflict on the research activities and acquisition of new data in the field-based sciences, the postconflict period shows signs of recovery in both domestic and international collaborations leading to again an accelerated growth in scientific publications.

Keywords: Bibliometrics; Web of Science, Co-word analysis; Research collaboration; Nepal; Citation impact; International co-authorship; Science mapping; Higher education; Developing country 


\section{Introduction}

Bibliometric analysis can be used as a quantitative tool to evaluate the past contribution to the science as a whole by research entities (individual or group of researchers, institutions, countries or even geopolitical units) and also to predict their future research potential (see Glänzel 2003 for details). Combining citation data with science mapping (e.g., for word, author, institution or country relationships among publications) further enables determining the regional and global networks of researchers, institutions, and countries along with quantification of the impact of research. The output and impact metrics accompanied with qualitative information help in effective formulation of national science policies, working out research development plans or revising them as well as making decisions related to funding (Moed 2005; Vinkler 2010). Despite the increasing popularity of the science and technology related bibliometric indicators in the developed countries that are also the focus of the world university rankings, many developing countries that are lagging in systematic collection of institutional research data still remain seldom studied by methods that are associated variously to bibliometry, scientometry and informetry.

This study first explores to what extent the scientific publications from Nepal are reflected in the core journal publications. Inspired by the recent initiative of the Nepal Academy of Science and Technology (NAST 2011) and sparse bibliometric studies on health research and air pollution in Nepal (Simkhada et al. 2010; Gurung \& Bell 2013), and the overall research output trends based on the Scopus-indexed S\&T records during 2001-2010 (Gupta \& Bala 2012), it then attempts a comprehensive analysis of the scientific output from Nepal based on more selective dataset but for a longer time span. The scientific output from Nepal during 2004-2013 recorded in the Web of Science database (WoS) has been subjected to detailed disciplinary analysis for share, impact and institutional/international co-authorship relationships. The results are believed to give further insights on research trends in a country that yet has to expand and consolidate research infrastructure to make the research output globally visible, and also raise the awareness of the rapidly growing young researchers' community towards the science and technology indicators.

\section{History of Modern Scientific Research in Nepal and Previous Bibliometric Studies}

\subsection{Development of Higher Education and Research in Nepal}

Research activities and publication practices in English-medium journals from Nepal didn't essentially begin until the sixties of the $20^{\text {th }}$ century owing to the 104 years (1846-1950) rule of the Rana Oligarchy, who kept the country virtually closed from the external world and also deprived the people even from basic education. The establishment of Tri-Chandra College in Kathmandu in 1918 marks the beginning of the western style tertiary level English-medium education, initially open to the elite members, in Nepal (Table 1). After the independence of country from Rana rulers in 1951 and the establishment of a democratic regime and monarchy, Nepal witnessed the emergence of Tribhuvan University (TU) in 1959 as the first institution offering higher education at both under-graduate and post-graduate levels. Nepal gradually opened up for foreign researchers, most of which were initially engaged in exploration of natural sciences such as geography, geology, flora and fauna of the Himalaya and adjacent regions. Gradually, their research and exploration interests shifted to agriculture, mountaineering, mountain sickness, tropical to subtropical diseases, glaciological research, etc. as will be demonstrated from the data in the later section.

\section{Table 1}


Figure 1 is the compilation of the Nepalese higher education and research organizations with demonstrated research contributions as peer-reviewed articles and reviews in the core research journals published almost exclusively outside the country. TU is the largest institution with about $90 \%$ share of enrollments in tertiary education, and as of 2015 it had 38 central departments offering postgraduate education, the highest number of campuses (60), and several hundred affiliated institutes and colleges (including medical colleges and hospitals) throughout Nepal (http://tribhuvan-university.edu.np/). Education in the bachelor's and master's levels in universities shown in Fig. 1 is course-based with limited opportunities for students' independent research (with some exceptions of involvement of a dissertation component in some fields, such as geology, in master's level). Hence, the doctoral level education in areas of specific importance to Nepal and clinical practice in teaching hospitals provide opportunities for student-led research activities that result in publications in scientific journals.

\section{------ Figure 1}

\subsection{Previous bibliometric studies on Nepal}

Gupta \& Bala (2013) performed a bibliometric analysis of 4,443 papers (presumably, all kinds of citable items: articles, reviews, book chapters, conference papers, notes and short surveys) produced by Nepal during 2001-2010 and indexed in Elsevier's Scopus database. With an annual growth rate of publications at ca. $16 \%$, the majority of publications were attributed to health sciences $(61.3 \%)$ followed by life sciences $(26.8 \%)$, physical sciences $(16.5 \%)$, and engineering sciences $(6.4 \%)$. In terms of the publication share in 27 subject areas used by Scopus, Gupta \& Bala (2013) suggested four groups:

(i) Highly productive (national share: $10 \%$ or more): medicine, agricultural \& biological sciences;

(ii) Medium productive (national share: 3\% or more but below 10\%): environmental science, biochemistry, genetics \& molecular biology, immunology \& microbiology, earth \& planetary sciences;

(iii) Low productive (national share: 1-3\%): engineering, pharmacology toxicology \& pharmaceutics, chemistry, physics, nursing, energy, public health, veterinary science, computer science, and materials science; and,

(iv) Least productive (national share: $0.5-1 \%$ ): neurosciences, chemical engineering, and, mathematics, and dentistry.

Judging from the Scopus-based citation impact calculated using raw citations per paper, Gupta \& Bala (2013) suggested six most impactful areas: immunology \& microbiology, earth and planetary sciences, biochemistry genetics and molecular biology, chemistry, public health, and physics. Highly productive areas (medicine, agricultural and biological sciences) had moderate citation impact. The overall international collaborative share judged on the basis of co-authorship in publications was $42.1 \%$, and the top five collaborating countries were USA, India, Japan, UK and Germany. Among Scopus's 27 subject areas, the international co-authorship ranged from $21.7 \%$ (dentistry) to $78.3 \%$ (earth \& planetary sciences). Agricultural \& biological sciences and medicine, included into the highly productive group, exhibited highly contrasting international co-authorships of $74.5 \%$ and $28.8 \%$. Top five domestic institutions (percentage of contribution) producing ca. 38\% of the total research output recorded in Scopus were identified as TU (13.8\%), BPKIHS (10.6\%), Manipal College of Medical Sciences, Pokhara (5.6\%), Kathmandu Medical College (3.8\%), and Kathmandu University (3.8\%).

Gurung \& Bell (2013) searched for literature on air pollution and human health in Nepal and found 89 studies, of which 23 were related to air pollution and health impacts and the rest focused on exposure and air quality.

Moed \& Halevi (2014) tracked the development and collaborations of 25 Asian countries including Nepal using the scientific output recorded in Scopus during 1997-2012. They placed Nepal besides Sri Lanka compared to which its performance was lower in productivity (the average number of publications 
per year), doctoral enrolments and their contribution to published science, number of full-time equivalent researchers and their publications, but higher in compound annual growth rate. Concerning the regional scientific collaborations, several countries in the South Asian region, namely, Si Lanka, Brunei, Nepal, Laos, Cambodia, Vietnam and Myanmar were shown to form a closely connected group called as the 'third cluster' with Thailand acting as a hub. This cluster dealt mostly with agriculture, medicine and earth sciences. Concerning the international scientific collaboration, USA occupied the central position, whereas UK was one of the players serving as a bridge between Laos, Cambodia, Myanmar, Nepal, Bangladesh, Bhutan and others and the European scientific community. It was clearly noted that smaller countries like Nepal, Bhutan and Sri Lanka are entering the scientific arena through increasing international co-authorships networks led by China, Japan, Thailand and others. Moed \& Halevi (2014) suggested that engagement in such collaborative networks has enabled these countries to gain expertise and increase their scientific output.

\section{Materials and Methods}

\subsection{Data retrieval and processing}

In order to have general idea about the research trend of Nepal, at first, bibliographic data related to publications in core collections during 1966-2016 recorded in WoS comprising SCI(E), SSCI, A\&HCI and ESCI database modules were searched for at least one author affiliation located in Nepal with the search string $\mathrm{AD}=$ Nepal. The search results were further narrowed down to include article and review types, commonly believed to yield reliable data through citation-based analysis, to yield 6,733 documents. Further manual check led to removal of 75 documents (ca. 1.1\%) containing Nepal in phrases like "5 Nepal Pk, Singapore" or "Canada Fdn Nepal, Ottawa", which do not imply affiliation to Nepal. Hence, the total number of 1966-2016 core journal documents from Nepal is 6,658 (Fig. 2). Several databases (WoS, Essential Science Indicators (ESI) and analytical tool (InCites) used for impact indicators) were accessed from web (http://ipscience.thomsonreuters.com/product/) at Hokkaido University under a license agreement formerly with Thomson Reuters and currently with Clarivate Analytics.

\subsection{Identification of basic publication trends and discrimination of periods for comparative analysis}

The overall publication trend was determined using a plot of the number of publications against the publication year. A bar plot of the annual change in publications (averaged over a 5-yrs window) was used to discriminate characteristic periods of publication growth or stagnancy. Two subsets for 19942003 and 2004-2013 were used for comparison of progress in research during two decadal periods in quantitative terms and also to see qualitative changes through the construction of science maps using VOSviewer (Van Eck \& Waltman 2010, 2014; Gautam \& Yanagiya 2012).

\subsection{Detailed bibliometric analysis}

The scientific publications, i.e. articles and reviews appearing in WOS-indexed journals assigned with impact factor, for the period 2004-2013 were subjected to analysis for the following discipline-level bibliometric indicators:

(i) Number of documents in each discipline forming the 22 ESI fields, $\mathrm{N}_{\text {doc. }}$. It is the indicator of the production of scientific publications by subject area during the period concerned. The whole counting method, by which each entity (country, institution) participating in the production of a document gets full credit (i.e., 1), has been used throughout this paper. As the publishing practices vary with discipline (e.g., researchers in chemistry publish far more papers in average than those in mathematics), this number may not be used for direct comparison of performance across disciplines.

(ii) Percent disciplinary share, $\%$ share $=100 * \mathrm{~N}_{\mathrm{doc}} / \mathrm{n}(\%)$. It indicates the relative share of each discipline out of the total scientific publications (n).

(iii) Number of papers, in each discipline, with citation percentile equal or below $10, \mathrm{~N}_{\text {Top10. }}$. It is derived using the value of citation percentile (0-100) for each document in InCites. 
(iv) Percentage of top $10 \%$ papers, PPTop $10=100 * \mathrm{~N}_{\text {Top } 10} / \mathrm{N}_{\text {doc }}(\%)$. Also denoted by Q, it is assumed as the proxy of quality of the set of publications considered. By definition, a value of $10 \%$ means performance equal to the world average.

(v) Discipline level category normalized citation impact (CNCI) averaged over Ndoc documents. CNCI of each document was extracted from InCites, where it is calculated by dividing the actual count of citing items by the expected citation rate for documents with the same document type, year of publication and subject area. CNCI is considered as a valuable and unbiased indicator of impact irrespective of age, subject focus of document type, and a value of 1 represents performance at par with world average. For discipline with a small $\mathrm{n}_{\mathrm{doc}}$, however, the CNCI values may be inflated by a single highly cited document.

(vi) Percent international collaboration or co-authorship by discipline, $\%$ IC $=100 * \mathrm{Ndoc}(\mathrm{IC}) / \mathrm{Ndoc}$ $(\%)$, where $\mathrm{Ndoc}(\mathrm{IC})$ is the number of documents in which at least one affiliating country is other than Nepal.

(vii) Percent disciplinary contribution of a research entity (country or institution), \% contr= $100 * \operatorname{Ndoc}(\mathrm{e}) / \mathrm{Ndoc}$, where $\mathrm{Ndoc}(\mathrm{e})$ denotes the number of documents related to the entity.

(viii) Activity index (AI), following the proposal of Frame (1977), as the ratio of the percent disciplinary share at country level to the percent disciplinary share at global level. The disciplines considered were ESI fields, and the global data for 2004-2013 for each field were taken from InCites. AI is an indicator of the comparative advantage of the given field within the country compared to that worldwide.

(ix) Relative Specialisation index, RSI=(AI-1)/(AI+1), after Glänzel (2000). For a given field, RSI ranges between -1 (completely idle field) through 0 (globally average or completely balanced activity) to +1 (activity only in that field). Any field with positive value (RSI $>0$ ) can be said to have higher-than-average activity, while that with negative value $(\mathrm{RSI}<0)$ reflects a lower-than-average activity.

Co-authorship relationship among the most productive countries collaborating with Nepal was visualised using VOSviewer (Van Eck \& Waltman 2010). Most prolific and leading collaborators (countries, institutions) were determined by counting the frequency of occurrence of each of them in affiliations of any and the first author only (Asghar et al. 2017).

\section{Results of Analysis}

\subsection{Research trend}

The WoS-recorded core collections from Nepal since 1966 shown in Fig. 2 exhibit an exponential growth with time. Detailed observations on the publication volume, however, suggest the presence of three distinct periods:

(i) Pioneering period (before 1989)

This period has low annual volume and no distinct trend. TU was the sole national academic institution to pursue research, but it was then basically concentrated in enhancing its educational capability targeted at the undergraduate programs. The affiliation at TU appears in one-third of the publications in this period. The other Nepalese entities contributing to $2-5 \%$ of total publications were as follows: Bir Hospital, Shanta Bhawan (Patan) Hospital, Ministry of Health (Family Planning \& Maternal Health Project), Department of Mines \& Geology, and International Center for Integrated Mountain Development (ICIMOD).

(ii) Period of growth and stagnation (1990-2005)

During this period, the publication volume steadily increased on annual basis during the first half but could not keep its pace during the second half. Growth in research activities in this period (1990-2005) is related to the increased opportunities of participation of Nepalese researchers in collaborative studies with scientists from abroad since the second half of the eighties, often the former being as a part of doctoral or postdoctoral programs at foreign universities, and also opening up of several doctor course programs leading to Ph.D. at TU and opportunities for advanced collaborative studies with foreign scholars visiting Nepal for 
research purpose. Establishment of Kathmandu University (KU) and BP Koirala Institute of Health Sciences (BPKIHS) and attraction of foreign researchers to them resulted in the diversification of research activities and further growth in research publications. Unfortunately, the second half of this period was characterized by stagnation attributable to the peoples' war initiated in 1996. With the deterioration of the political situation due to intensification of the government-Maoist conflict, access to the countryside became very much restricted and therefore hindered the field-based research activities both by domestic and foreign researchers. Earth and environmental sciences and agroforestry studies are believed to be the hardest hit areas during this time.

(iii) Period of acceleration (2006-present)

This period is characterized by a rapid and truly exponential annual growth. The last 2 years (2015 and 2016) have been especially productive due to the proliferation of publications in the aftermath of the devastating Gorkha Earthquake (7.8 magnitude in Richter scale) that triggered internationally collaborative field research in seismology (e.g., Miyake et al. 2017), engineering geology, civil engineering and other fields. The end of the peoples' war in 2006, abolition of monarchy and establishment of new democratic Nepal paved ways for further access to Nepal and its countryside for research and, though with some time lag, resulted in an accelerated growth of research activities and output as publications in academic journals again.

\section{------ Figure 2}

\subsection{Semantic term maps as indicators of priority research areas and their shifts at a decadal scale}

Two science maps of terms and noun phrases in titles \& abstracts of publications for two consecutive decades (1994-2003 and 2004-2013) in Figs. 3 \& 4 provide clues on the major research areas in Nepal. Four prominent clusters, each of which is defined by terms or noun phrases occurring at least eight times, are recognized for the first period (Fig. 3). The largest cluster (Fig. 3) combining two themes, (i) child \& maternal health, and (ii) vision \& mountain sickness, seems to have developed in the next period into two distinct and integrative clusters (Fig. 4). Four additional clusters are identified in Fig. 4. Comparison of maps in Figs. 3 and 4 reveals that four clusters (child \& maternal health, family planning; clinical medicine, tumour, mountain sickness; infectious diseases; and, agroforestry) in the latter represent the expanded and cross-disciplinary versions of the research areas initiated during the former period. In the case of agriculture, research focus related to staple foods seems to have shifted from rice during 1994-2003 to wheat in the next 10-years period. In addition, research on protein structure analysis $\&$ synthesis developed as a new prominent area during 2004-2013. Continuity of research themes from the preceding 10-years period with further expansion and diversification of research output is obvious from these maps. Because of the very little progress in research during the second half of the first period, detailed bibliometric analysis hereafter will focus on the 2004-2013 period when the political situation in Nepal returned to normalcy being again favourable for domestic as well as international collaborative research.

\subsection{Disciplinary coverage, share, and impact of 2004-2013 publications}

Disciplinary coverage of the scientific publications is shown in Table 2. Among the 22 ESI fields, seven fields represent more than $80 \%$ of total publications. Clinical medicine has the highest share $(40 \%)$, followed by plant \& animal science and environment/ecology (10\% each), social sciences $(8 \%)$, geosciences and agricultural sciences (about 5\% each) and chemistry (slightly less than 4\%). The first six prolific ESI fields yield moderately positive RSI values: Environment/ecology (0.51); social sciences, general (0.35), agricultural sciences (0.35); geosciences $(0.33)$; plant \& animal science $(0.31)$, 
and clinical medicine (0.26). The seventh field (chemistry) and the less prolific fields such as engineering, physics, materials science yield RSI value lower than -0.5. In simple terms, following Glänzel (2000), the activity of the first six fields can be said to be well above the global average, while the opposite (i.e., almost half of the world average) is true for the others.

Table 2 shows PPTop10 (\%) and CNCI used together as impact indicators that take into account the differences in citation counts among the fields. The citation impact according to CNCI or PPTop10 is above the world average for geosciences (the highest impact), clinical medicine and agricultural sciences, while for additional four prolific fields, the impact is well below the world average decreasing in the sequence of social sciences, chemistry, environment/ecology and plant $\&$ animal science. Among the fields with a lower publication share varying between $0.7-2.2 \%$, the citation impact is distinctly above the world average for molecular biology \& genetics, economics \& business, psychiatry \& psychology, materials science and biology \& biochemistry, whereas it is close to the world average for pharmacology \& toxicology, microbiology, and immunology. Physics and engineering fields exhibit impacts slightly higher than half of the world average, whereas neuroscience \& behaviour, mathematics and space science have very low impact.

\section{Table 2}

Figure 3

\section{----- Figure 4}

\subsection{Degree of collaborations at country, institution and discipline levels}

The core journal publications related to Nepal, all published outside Nepal except for a single journal (i.e., Journal of the Nepal Medical Association), show very high degree of international collaboration $(76.4 \%)$, covering the topics of broad international interest. Figure 5 shows the co-authorship relations for countries with at least ten collaborative papers with Nepal during 2004-2013. For countries and institutions, publications with any authorship and first authorship were counted. These data for top 40 countries and institutions are shown Fig. 6. Top ten foreign countries contributing to these publications with any authorship type are as follows: USA, India, UK, Japan, South Korea, Germany, Peoples R China, Australia, Switzerland, and Thailand (for percentage values, see bottom line Table 3). Among the foreign institutions, leading contributors with first authorship are recognized as Johns Hopkins Univ (USA), Chonbuk Natl Univ (South Korea), Chinese Acad Sci (Peoples R China), Inst Trop Med (Belgium), Banaras Hindu Univ (India), Univ Tokyo (Japan), London Sch Hyg \& Trop Med (UK), TM Bhagalpur Univ (India) and Univ Calif San Francisco (USA), Univ Washington (USA), Univ Coll London (UK), and Natl Inst Adv Ind Sci \& Technol (Japan).

Table 3 gives an extensive list of the diverse and important contributors (top five countries and top five institutions) identified for each discipline for the last 2004-2013 period. It proves that Nepal continues to be a venue of collaborative research in diverse disciplines. The lowest international co-authorships observed in clinical medicine $(56.5 \%)$ and neuroscience \& behavior (61.1\%) suggest that domestic institutions are in relatively better position to conduct independent research in these fields compared to others. The $100 \%$ international co-authorship seen for molecular biology \& genetics and space science may imply that the country still largely relies on collaboration with foreign countries to conduct and publish research results. Among the relatively better productive fields, international co-authorship stands at $91-96 \%$ for geosciences, agricultural sciences, and chemistry, whereas it is $78-83 \%$ for environment/ecology, social sciences (general), plant \& animal science. These facts suggest that a lot 
still needs to be done to develop research capacity in order to ensure that more Nepal-based researchers become able to increase the submissions of research results to the peer-reviewed international journals.

\section{----- Figure 5}

Table 3

----- Figure 6

\section{Discussion}

5.1 General issues related to comparison of results of bibliometric analysis based on different databases

Of the three databases (WoS, Scopus and Google Scholar) currently available for citation-based analysis of research output, the first two commercial products are routinely used for their informed and systematic coverage of publications from sources that are judged to meet their own pre-set criteria fit for inclusion into them. As any analysis based on Google Scholar seems to be unavailable for Nepal, comparison here is limited to the other two databases. Even for an identical period of analysis, interpretations on qualitative and quantitative research performance indicators derived from WoS and Scopus records may vary owing to (i) the differences in the journal coverage policies and practices that determine the publication volume; (ii) the document types and their definitions (e.g., articles, reviews, conference papers, notes), and; (iii) the database access dates. Differences in the journal coverage seems to be the most imortant reason for differing scholarly outputs for the same research entity in these two databases. For example, Journal of the Nepal Medical Association is the only domestic journal from Nepal indexed in the core collections, whereas Scopus's list is more extensive as it already had a significant records from additional domestic journals such as Kathmandu University Medical Journal, Nepal Medical college Journal, Journal of the Nepal Paediatric Society, Nepalese Journal of Ophthalmology already at the time of analysis by Gupta \& Bala (2013). This fact directly implies that a vast body of documents published in the Nepali domestic journals continues to be invisible in WoS, while a large share of publications related to medical fields, at the least, has been made globally visible via Scopus. With regard to the disciplinary schemes, each publication indexed in Scopus is assigned to one of the 27 subject areas (following the All Science Journal Classifications (ASJC) scheme) depending upon the journal that carries it, whereas the most widely used disciplinary scheme for WoS-indexed publications is the ESI (22 fields) scheme in which each publication is assigned to a unique category depending on the journal carrying it or occasionally the disciplinary affinity of the reference cited by the papers appearing in multidisciplinary journals (Vieira \& Gomes 2009; Gautam 2016). Despite the difficulty to directly compare the inferences from studies derived from bibliographic records and citations drawn from the different databases, at first, an attempt is made to compare the results of this study with those by Gupta \& Bala (2013) to understand the publication volume and its impact. The aspects of publication profile, international collaboration, and state of development of science and technology in Nepal will be discussed thereafter.

\subsection{Publication volume and citation impact}

To ensure a rough yet more realistic comparison, the disciplinary dataset for 5-years period of 20062010 common to this study (a total of 1,394 papers) and Gupta \& Bala (2013) (a total of 2,954 papers) will be used. Table 4 shows an informal grouping of documents in broadly similar prolific disciplinary areas amounting to 1,183 articles \& reviews in WoS but 2,661 citable items (after correction for 1.23 times in average exaggeration due to multi-category assignment of the same item) in Scopus, covering the respective shares of about $90 \%$. Five broad and informal groups have been suggested: 'medical \& health sciences', 'agricultural, biological and life sciences', 'environmental sciences', 'earth and space sciences, and 'engineering and chemical sciences' (Table 4). These data imply that the Scopus-based 
study by Gupta \& Bala (2013) has captured 2.25 times more documents than the present WoS-based study.

\section{----- Table 4}

Among the seven fields recognized in this study as prolific for the 2004-2013 period, the field of geosciences has highest impact (PPTop10\% $=22.1 \%$; $\mathrm{CNCI}=1.70$ ). Clinical medicine is found to be the next high impact field $(\mathrm{CNCI}=1.27)$. Environment/ecology, agricultural sciences, and chemistry are three fields positioned around the global average. Social sciences and plant \& animal science exhibit citation impact almost half of the global average. These findings are in agreement with the conclusions of Gupta \& Bala (2013) concerning the earth and planetary sciences judged as high impact area and agricultural sciences as the moderate impact area related to 2001-2010 period and based on raw, rather than field-normalized, citations per paper. For other disciplines, however, the findings about the citation impact differ among the two studies. The differences in the publications volume and citation impact in medicine-related discipline are believed to be due to several reasons: database-dependent difference in the coverage of Nepal-based journals, differences in the proportion of papers related to clinical medicine and other medical fields and the differences in their citation patterns, the difference in the international co-authorship percentage in Scopus-based medicine (28.8\%) and WoS-based clinical medicine $(56.5 \%)$, dissimilar judgement based on raw and field-normalized citations data, among others.

\subsection{Publication profile of Nepal}

The issue related to medicine and social sciences discussed above can be addressed partially using the findings from a new and complementary study of the 2004-2013 dataset for WoS 251 subject categories (SCs), to each of which one or more documents can be assigned (Gautam 2017). The new study reveals that $200 \mathrm{WoS}$ SCs, 179 of them with at least 2 documents and 17 with at least $61(2 \%)$ documents each, characterize the 3,011 publications considered. The "public, environmental \& occupational health" is the largest SC with 680 publications (i.e., every fifth). It shares 356, 226 and 16 publications with 3 ESI fields, namely "clinical medicine", "social sciences, general" and "environment/ecology", respectively. In other words, research output from the public health sector contributes to one third of the research in clinical medicine and also most of the disciplinary contribution attributed to the social sciences according to the ESI scheme (Table 2). Following Glänzel (2000), the moderately positive RSI values for all six prolific fields (see section 4.3 above) and this observation of the prominence of public health research can be used to suggest that the research profile of Nepal is a hybrid of the bio-environmental and western models. The "bio-environmental model" was used to explain the pattern characteristic of developing and more "natural" countries with biology, earth and space science in the main focus, whereas the "western model" was used to characterize the predominance of clinical medicine and biomedical research (Glänzel 2000),

A discussion on the state of research and education on biomedical and health sciences sharing half of the publications from Nepal is appropriate here. Research in clinical medicine (including public health) grew rapidly after around 1990. Significant developments in establishing medical institutes and colleges resulting in "a leap in medical education" discussed by Adhikary (2013), and the nearly fifty-fold increase in medical students trained in Nepal in 15 years period, primarily through the creation of private medical schools, observed by Huntington et al. (2012), indirectly and independently explain this growth. Establishments of a dozen of medical colleges, independent or affiliated to existing universities, after the second half of the 1990-2000 and engagement in research and education of an increasing number of medical faculties, a significant number of which came from abroad under academic exchange and research \& education agreements, as well as the involvement of graduate students in clinical practice in teaching hospitals resulted in publications of a significant number of case histories as internationally collaborative papers. Table 5, based on data from Adhikary (2013), shows that the number of medical doctors in Nepal has significantly increased with time. Another dataset by the same author shows that 3 major domestic medical institutions (TU, BPKIHS and KU) have produced 8,168 graduates in between 1984 and 2012. Hence, the progress in research in medicine seems to have been driven by internal factors that owe to the notable advances in research and education in medical sector in Nepal. Huntington et al. (2012) noted that despite the large-scale production of new physicians, there is an oversupply in the 
cities but rural and remote areas remain largely underserved. They advocate for creation of more postgraduate training positions in Nepali institutions with emphasis on continued training needed by rural Nepal, e.g. medical doctorate in general practice, general surgery, women's health and community medicine. Successful implementation of such measures is very much desirable, as this will surely lead to increased opportunity for further promotion of research in clinical medicine, or 'medical and health science' in a broader sense, and its consolidation in Nepal.

The emergence of the bio-environmental sector as the second internationally visible research field is the result of continued efforts to create research and education bases in Nepal's academic institutions (primarily TU and KU), national institutions (Department of Mines \& Geology, Nepal Agricultural Research Council, Department of Agriculture, Nepal Academy of Science \& Technology, Department of Hydrology \& Meteorology), Nepal-based international and domestic non-governmental/non-profit organizations (International Center for Integrated Mountain Development, King Mahendra Trust for Nature Conservation, Department of National Park \& Wildlife Conservation), and private research organizations (Research Laboratory for Biotechnology \& Biochemistry, Environmental \& Public Health Organization) and so on. The research output of 200-300 publications assigned to each of the WoS SCs related to the biological, environmental, geological, and agricultural disciplines, related to this field in a broader sense, is the result of a very effective international collaboration with foreign institutions. Such an outcome owes very much to the fact that Nepal continues to be a venue of collaborative research in these disciplines owing to its unique field settings, characterized by the diversities in geology, biology and ecology/environment/climate in the heart of the Himalayas.

\section{Table 5}

\subsection{International collaboration}

It is believed that inter-university collaboration forms the major source of publications where engagement of one or more co-authors from Nepal is involved. The Nepali or Nepal-based author is in most cases likely to have a role either of a graduate student (master's or doctoral level) or a postdoctoral fellow in a foreign country while he or she at the same time occupies a faculty position in Nepal. Of course, the same person continues collaborative research with foreign institutions even if he/she may not have direct affiliation with a foreign university. Kato \& Chayama (2010) note that this kind of coauthorship (i.e., driven by doctoral studentships at a foreign university and continued collaboration after returning to the home institution) is significant in case of papers produced by the Philippines or Indonesia and Japan, which has increased the acceptance of foreign students and international cooperation leading to increasing exchange in recent years.

This study used the number of papers in which a country other than Nepal and foreign institution appeared in affiliation strings as a simple proxy of that country's overall (or disciplinary) contribution in the form of international collaboration, and identified top ten (or five) countries. Following the approach of Asghar et al. (2017), the data related to the first authorship also were obtained. Because of the analysis of WoS core collections almost exclusively in English, many regionally and locally important journals outside the WoS sphere but reporting a significant portion of research involving developing countries and their institutions in English and other languages (e.g., Japanese and French, known to contribute to science) with a co-author from Nepal could not be captured. Hence, readers need to pay attention to the possible incomplete nature of the proposed list and order of top contributors.

\subsection{The state of scientific development of Nepal}

Following the end of its political and economic isolation in 1951, Nepal established TU in 1959 and started providing postgraduate level education in several subjects. It took another 20 years to expand the research infrastructure and build national research capacity to reach an internationally visible level of research output as shown above (Fig. 2). Despite the notable growth in the scientific publications towards the late 1980s, a period of stagnation (virtually constant growth or even its decrease) followed 
after the Mid 1990s. Such stagnation is attributed to the changing political situation in Nepal, namely the decade long peoples' war or Maoist Insurgency - an armed rebellion initiated by Nepalese Maoists in 1996 against the Royal Government of Nepal of that time (Adhikari \& Samford 2013). That situation led to a drastically reduced access to the field, be it in the field-based clinical medicine or agricultural and geo-environmental disciplines, for research in Nepal by researchers irrespective of their Nepali or foreign nationality.

Improvements in the political situation around 2004 and termination of the people's war in 2006 leading to the abolition of monarchy and establishment of political freedom resulted in renewed access to research in broader disciplines in an increasingly collaborative and participatory atmosphere. An accelerated growth in research activities and publications seen in Fig. 2 proves this. Publications (articles and reviews) recorded in WoS for 2004-2013 counted thrice as much as that for the previous 10-yrs period (1994-2003). Based on the marked growth in publications, diversity of disciplines, engagements of academic, governmental research institutions, and non-governmental/non-profit organizations, and very high degree of international collaboration observed in this study, Nepal's state of scientific development corresponds basically to the 'building-up' stage of Moed \& Halevi (2013). In some disciplines like the clinical medicine and geosciences, however, there are demonstrated research strengths by the publication volume and/or the citation impact. National and institutional efforts are required to formulate structured research programs at academic and research institutions along with adequate funding to attract and retain young talents and upgrade the physical infrastructure and equipment aimed at promoting the cutting-edge research for a fuller transition to the "consolidation and expansion' stage (Moed \& Halevi 2013).

\section{Limitations of this study}

Being based on the selective research output (articles and reviews) from Nepal recorded in WoS that has strict selection criteria regarding the quality of journals, this study highlighted the most globally visible research produced often by collaborative teams in which at least one author was based in Nepal. The real volume of research output from Nepal published in domestic and international (outside Nepal) journals not indexed in WoS is much higher. This is evident for example from the web page of Nepal Journal Online (an online all-disciplinary database of journals, published in Nepal and fulfilling certain inclusion criteria: originality of research, peer review and quality control), which contains a list of 118 journals comprising 12,612 articles (NepJol 2017), which is twice as much as the whole 1966-2016 record in WoS. The concerns raised by Rafols et al. (2015) and Yegros-Yegros et al. (2016) for possible under-representation of publications addressing the needs specific to the developing countries or the socalled global south (e.g., research on crops such as rice and neglected tropical diseases that are related to clinical medicine) in the WoS and Scopus also point to need to the search of publications in other databases. It is therefore desirable that future studies aimed at a comprehensive bibliometric study consider all possible databases paying attention to the quality criteria. There is also a need to compare the research output from Nepal under a broader regional context (e.g., the South Asian Association for Regional Cooperation (SAARC) member countries) with due focus on the specializations of each country involved (Bajwa \& Yaldram 2012; Mahbuba \& Rousseau 2010).

\section{Conclusions}

The major findings of this study on the WoS indexed scientific publications from Nepal can be summarized as follows:

(1) The scientific publications related to Nepal started to grow towards the late 1980s. A period of stagnation followed after the Mid 1990s and lasted for about a decade owing to the peoples' war. During 2004-2013, marked by renewed accelerated growth of research output from Nepal, the publications counted 3,011 that is thrice as much as that produced during the preceding decade (1994-2003). 
(2) The core journal publications related to Nepal show very high degree of international collaboration (76.4\%), covering the topics of broad international interest. Top collaborating countries, arranged in the decreasing order of contribution, were found to be the USA, India, UK, Japan and South Korea. Top domestic institutions contributing to publications were: TU, BPKIHS; KU, ICIMOD and Manipal Coll Med Sci \& Teaching Hosp. Likewise, top foreign institutions playing the leading role were found to be Johns Hopkins Univ, Chonbuk Natl Univ, Chinese Acad Sci, Inst Trop Med and Banaras Hindu Univ.

This study identified (i) the trend of internationally significant research output from Nepal as recorded in the WoS database for the period from 1966 to 2016, (ii) shifts in major research areas from 19942003 to 2004-2013, and (iii) the publication share, citation impact and collaborators (countries and institutions, both domestic and international) in terms of ESI 22 fields. These findings are believed to be useful for a range of users (academia, government agencies, corporate sector, international donor agencies, young researchers and graduate students, etc.) for different purposes (identifying research areas and research collaboration venues, formulation of science policy, identifying research partners for industry-academia collaboration, exploration of sectors that need priority in research funding, and selection of destinations for higher education and research, etc.). This study clearly demonstrates that the poor state of higher education coupled with the prevailing political and economic situations in a developing country like Nepal may have notable negative effect on the volume of scientific publications and their growth rate, whereas certain natural disasters, like a large earthquake that attracts the attention of researchers worldwide, may trigger the growth in a positive way. And, a bibliometric analysis combined with science mapping, with due account of the causative factors, serves as a powerful tool in assessment of the state of development of science and technology at the country level.

\section{Acknowledgements}

The author would like to express sincere gratitude to Dr. Yuji Sakakibara, former Director General of NISTEP, Tokyo, for giving very practical tips on rapid percentile analysis of bibliographic data in terms of scientific fields. Critical and constructive comments as well as encouragements by an anonymous reviewer and Professor Wolfgang Glänzel, the chief editor, on the earlier versions of the manuscript prompted renewed analyses by the author leading to significant additions and improvements in the revised manuscript. A part of this material was presented during the 10th International Conference on Webometrics, Informetrics and Scientometrics (WIS) held in Ilmenau, Germany.

\section{References}

Adhikari, P., \& Samford, S. (2013). The Nepali State and the dynamics of the Maoist insurgency. Studies in Comparative International Development, 48(4), 457-481. DOI:10.1007/s12116-012-9125-4

Adhikary, S. (2013). Chikitsa Shikshama Fadko (A leap in Medical Education in Nepal), Teacher Monthly, Lalitpur, 390 p. ISBN: 978-9937-8750-0-4 (in Nepali).

Asghar, I., Cang, S., \& Yu, H. (2017). Assistive technology for people with dementia: an overview and bibliometric study, Health Information \& Libraries Journal, 34: 5-19. DOI:10.1111/hir.12173

Bajwa, R.S., \& Yaldram, K. (2013). Bibliometric analysis of biotechnology research in Pakistan. Scientometrics, 95: 529. DOI:10.1007/s11192-012-0839-x

Frame, J. D. (1977). Mainstream research in Latin America and the Caribbean. Interciencia, 2, 143-148.

Gautam, P., \& Yanagiya, R. (2012). Reflection of cross-disciplinary research at Creative Research Institution (Hokkaido University) in the Web of Science database: appraisal and visualization using bibliometry. Scientometrics, 93(1), 101-111. DOI:10.1007/s11192-012-0655-3

Gautam, P. (2016). Comparative analysis of scientific publications of research entities using multiple disciplinary classifications. Proceedings of the 2016 IIAI $5^{\text {th }}$ International Congress on Advanced Applied Informatics, Kumamoto, Japan, 524-528. DOI:10.1109/IIAI-AAI.2016.117

Gautam, P. (2017). Detection of bibliographic coupling communities using research output (2004-2013) from Nepal. Proceedings of the 2017 IIAI 5th International Congress on Advanced Applied Informatics, Hamamatsu, Japan. (In Press). 
Glänzel, W. (2000). Science in Scandinavia: a bibliometric approach. Scientometrics, 48(2), 121-150.

Glänzel, W. (2003). A course on theory and application of bibliometric indicators. Course Handouts. https://www.researchgate.net/publication/242406991 (accessed on 2016/8/18).

Gupta, B. M., \& Bala, A. (2012). S\&T publications output of Nepal: a quantitative analysis, 2001-10. Scientometrics, 93(3), 1029-1046.

Gurung, A., \& Bell, M.L. (2013). The state of scientific evidence on air pollution and human health in Nepal. Environmental Research, 124, 54-64.

Huntington, I., Shrestha, S., Reich, Nicholas G., \& Hagopian, A. (2012). Career intentions of medical students in the setting of Nepal's rapidly expanding private medical education system. Health Policy and Planning, 27(5), 417-428. DOI:10.1093/heapol/czr052

Kato, M., \& Chayama, H. (2010). Analysis on research activities in developing countries and international networking of researchers. Research Material No. 178, National Institute of Science and Technology Policy (NISTEP), Ministry of Education, Culture, Sports, Science and Technology (MEXT), Japan.

Mahbuba, D., \& Rousseau, R. (2010). Scientific research in the Indian subcontinent: selected trends and indicators 1973-2007 comparing Bangladesh, Pakistan and Sri Lanka with India, the local giant. Scientometrics, 84(2),403-420.

Miyake, H., Sapkota, S. N., Upreti, B. N., Bollinger, L., Kobayashi, T., \& Takenaka, H. (2017). Preface. Special issue "The 2015 Gorkha, Nepal, earthquake and Himalayan studies: First results". Earth, Planets and Space 69:12. DOI:10.1186/s40623-016-0597-8

Moed, H. F. (2005). Citation analysis in research evaluation. Springer. ISBN 978-1-4020-3714-6

Moed, H., \& Halevi, G. (2014). Country Trends: Tracking scientific development and collaborations The case of 25 Asian counties. Research Trends, 38. http://www.researchtrends.com/issue-38september-2014/tracking-scientific-development-and-collaborations-the-case-of-25-asian-countries/

NAST (2011). Science and technology indicators of Nepal - 2010. Unpublished Report by Nepal Academy of Science and Technology, Lalitpur, Kathmandu, Nepal.

NepJol (2017). Nepal Journal Online www.nepjol.info (accessed 2017/05/19)

Rafols, I., Ciarli, T. \& Chavarro, D. (2015). Under-reporting research relevant to local needs in the global south. Database biases in the representation of knowledge on rice. Proceedings of ISSI 2015 Istanbul: 15th International Society of Scientometrics and Informetrics Conference, 598-599.

Simkhada, P. P., Baral, Y. R., \& van Teijlingen, E. R. (2010). Health and medical research in Nepal: a bibliometric review. Asia-Pacific Journal of Public Health 22(4), 492-500.

Van Eck, N. J., \& Waltman, L. (2010). Software survey: VOSviewer, a computer program for bibliometric mapping. Scientometrics, 84(2), 523-538, program online: http://www.vosviewer.com/ (February 2, 2014).

Van Eck, N. J., \& Waltman, L. (2014). Visualizing bibliometric networks. In Y. Ding et al. (Eds.), Measuring Scholarly Impact (pp. 285-320), DOI:10.1007/978-3-319-10377-8_13

Vieira, E. S., \& Gomes, J. A. N. F. (2009). A comparison of Scopus and Web of Science for a typical university. Scientometrics, 81(2), 587-600. DOI:10.1007/s11192-009-2178-0

Vinkler, P. (2010). The evaluation of research by scientometric indicators. Oxford, UK: Chandos Publishing.

Yegros-Yegros, A., Rafols, I., Abad-García, M.-F., Mugnaini, R., \& Meijer, I. (2016). Scientific research on diseases: the distinct profile of developed and developing countries. Book of Proceedings of the $21^{\text {st }}$ International Conference on Science and Technology Indicators, Valencia, Spain, 419423. DOI:10.4995/STI2016.2016.4543 


\section{Figure Captions}

Fig. 1 Sketch map of Nepal showing the boundaries of 14 administrative zones and locations of major cities, where the major academic and research establishments or headquarters (in the case of multiple campuses or branches of the same institution) are situated. Major national and public universities (numbered from 1 to 10) and other colleges, research establishments, and organizations that have significantly contributed to the research output from Nepal are also shown.

Fig. 2 Scientific publications (1966-2016) from Nepal retrieved from the Web of Science by searching for "Nepal" in address (AD) as the country of affiliation. The dots show the annual publication counts, while the fitted curve shows an exponential increase in publications since around 1975. The vertical bar plot, with each bar as the difference in publications between two consecutive years, shows the annual rate of change in the research output. Arrows and labels highlight the periods with differing publication patterns used for comparative and/or detailed analysis.

Fig. 3 Map of terms and noun phrases in titles \& abstracts of 1,004 publications from Nepal produced during 1994-2003. The map displays 4 prominent clusters, each of which is defined by terms or noun phrases occurring at least 8 times. The largest cluster seen here is a composite of 2 themes: (i) child \& maternal health, and (ii) vision \& mountain sickness.

Fig. 4 Map of terms and noun phrases in titles \& abstracts of 3,011 publications from Nepal produced during 2004-2013. Six prominent clusters defined by terms or noun phrases occurring at least 8 times, are identified.

Fig. 5 Map showing co-authorship relations for countries that produced at least 10 collaborative papers with Nepal during 2004-2013. The size of the nodes (countries) is proportional to the number of collaborative papers. The thickness of lines connecting nodes points to the intensity of collaboration. Color shades point to clusters as the sets of closely related nodes.

Fig. 6. List of top 40 foreign countries (left) and 40 foreign institutions (right) collaborating with Nepal identified from the 2004-2013 scientific publications. For clarity, the institutions (right) are grouped by country and at the same time arranged in the decreasing order of the number of papers with first authorship (a proxy of the leading role in the production of research results). 


\section{Table Captions}

Table 1 A brief history of establishment of higher education Institutions in Nepal

Table 2 Distribution of the WoS core journal publications (2004-2013) from Nepal into 22 disciplinary fields.

Table 3 Top five foreign collaborating countries, other than Nepal, and institutions (both from Nepal and abroad) by research fields covered by 3,011 core journal publications.

Table 4 Comparison of the prolific fields (> 4\% share) in the 2006-2010 publications indexed in Scopus and WoS.

Table 5 Growth in number of medical doctors in Nepal with time. 


\section{Figure 1}

\section{NEPAL}

Current Universities \& Selected Research Organizations

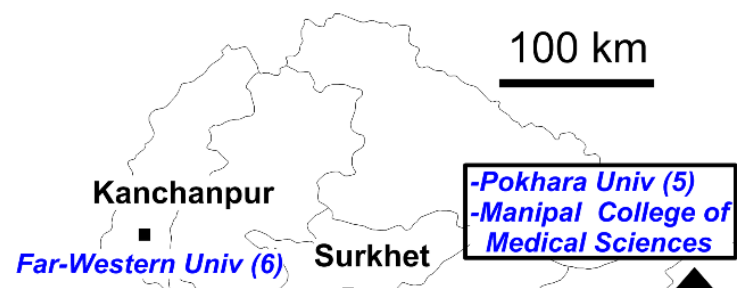

-Tribhuvan Univ (1) -Intl Ctr for Integrated

Mountain Development - Nepal Agr Res Council -UN World Food Program

Anandaban Hospital

- Nepal Acad Sci \& Technology -Natl Inst Neurological \&

Allied Sciences

-World Wildlife Fund Nepal -CIMMYT International

-Transcultural Psychosocial Organization Nepal

-Res Lab for Agr Biotech

and Biochemistry -Natl Seismological Ctr Mid-Western Univ (7) Dang

Nepal Sanskrit Univ (8) Pokhara

\section{Kathmandu} Lalitpur

Lumbini - Dhulikhel

Lumbini Bouddha Univ (9) Rampur Bharatpur Kathmandu Univ (2)

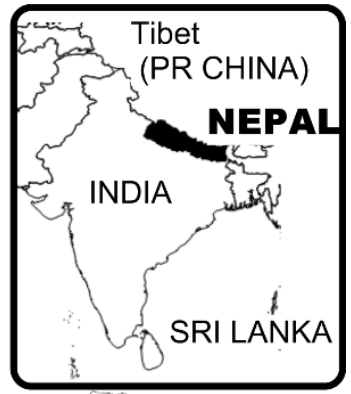

\section{Nepal Agriculture College of Medical Dharan BP Koirala Institute} \& Forestry Univ (10) Sciences \& Hospital - Biratnagar

Purbanchal Univ (4) 


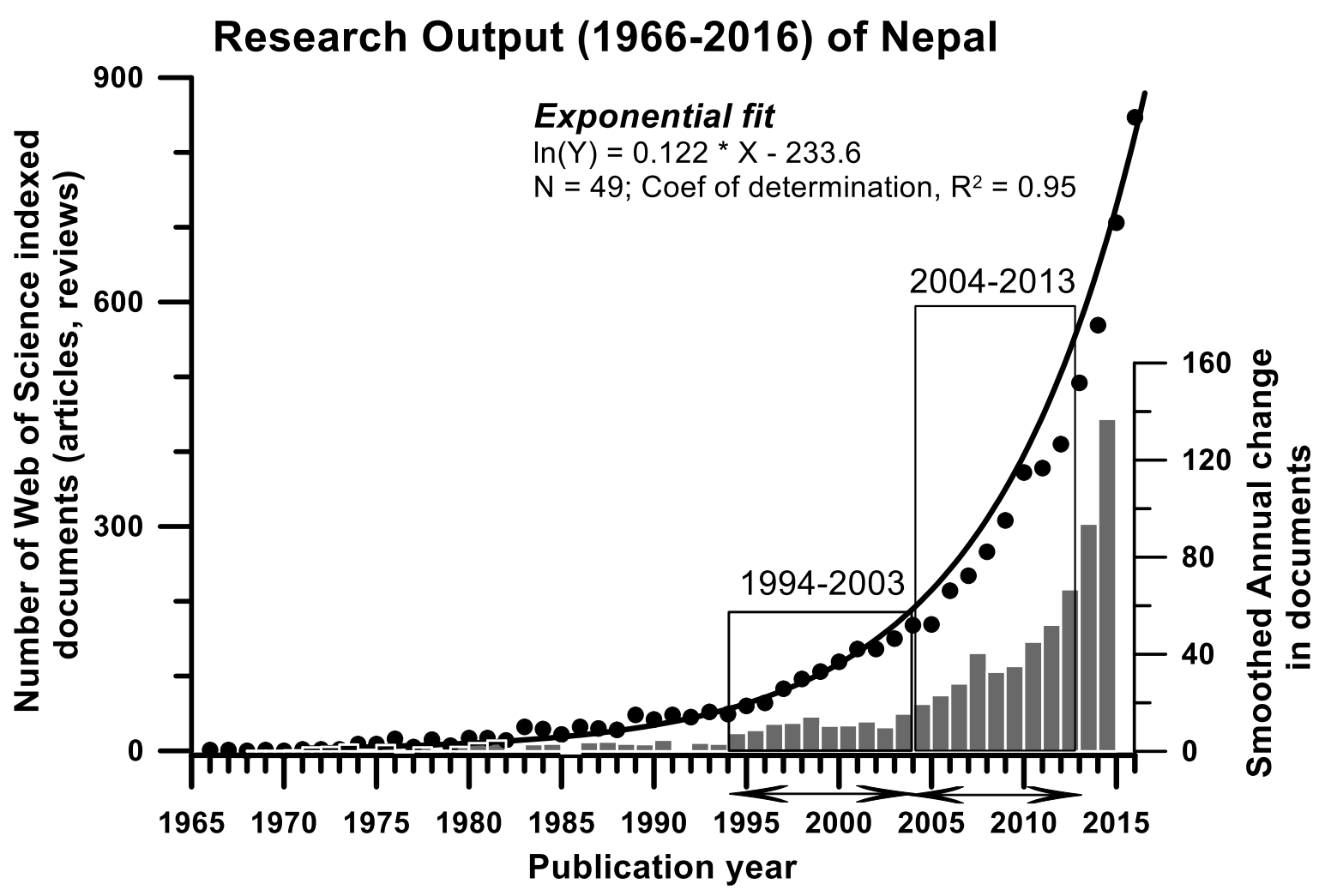


1

2

3

4

5

6

7

8

9

\section{Figure 3}

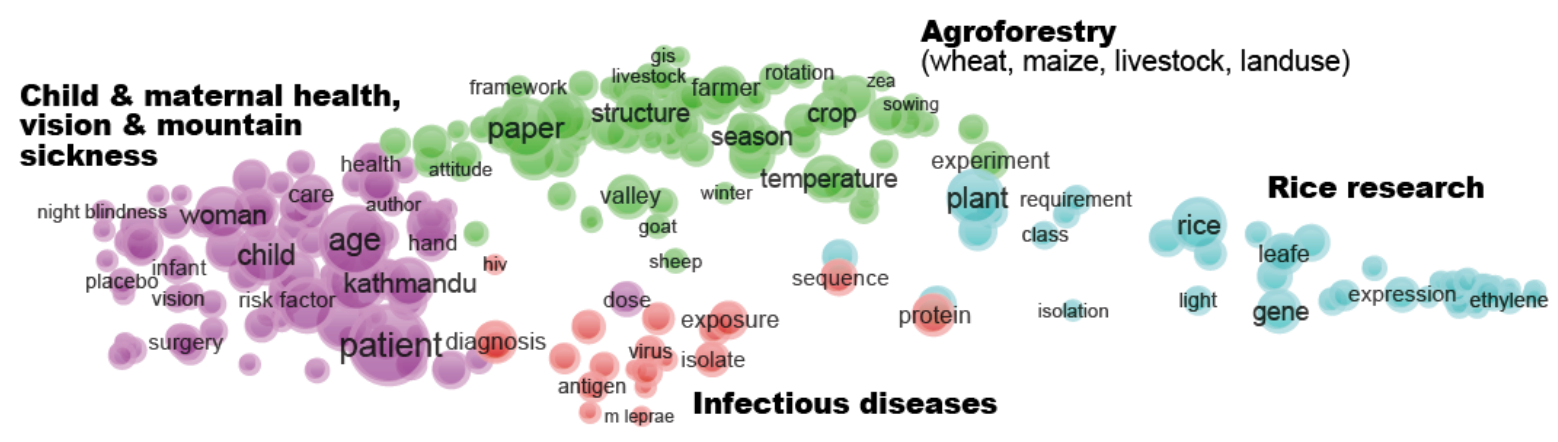


Figure 4

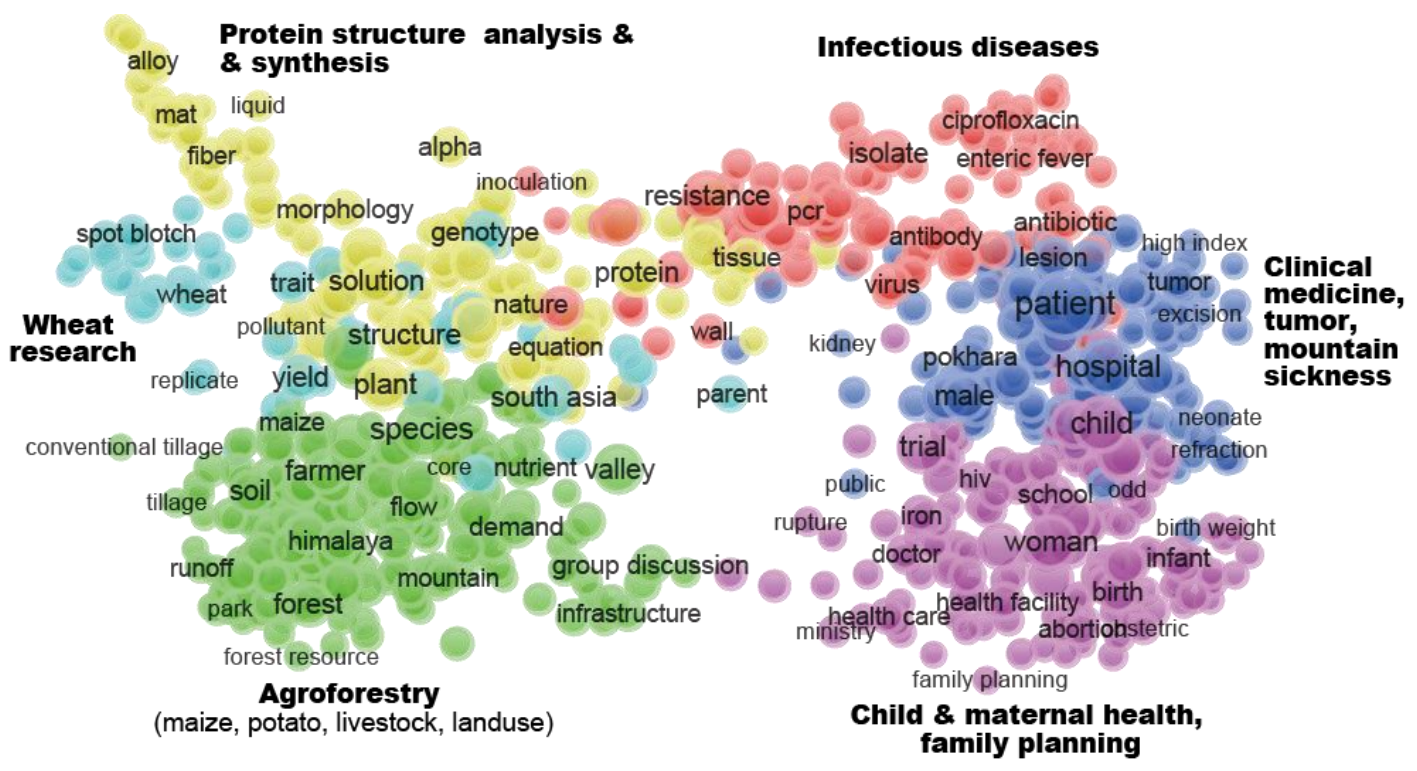




\section{Figure 5}

1

2

3

4

5

6

7

8

9

10

11

12

13

14

15

16

17

18

19

20

21

22

23

24

25

26

27

28

29

30

31

32

33

34

35

36

37

38

39

40

41

42

43

44

45

46

47

48

49

50

51

52

53

54

55

56

57

58

59

60

61

62

63

64

65

belgium
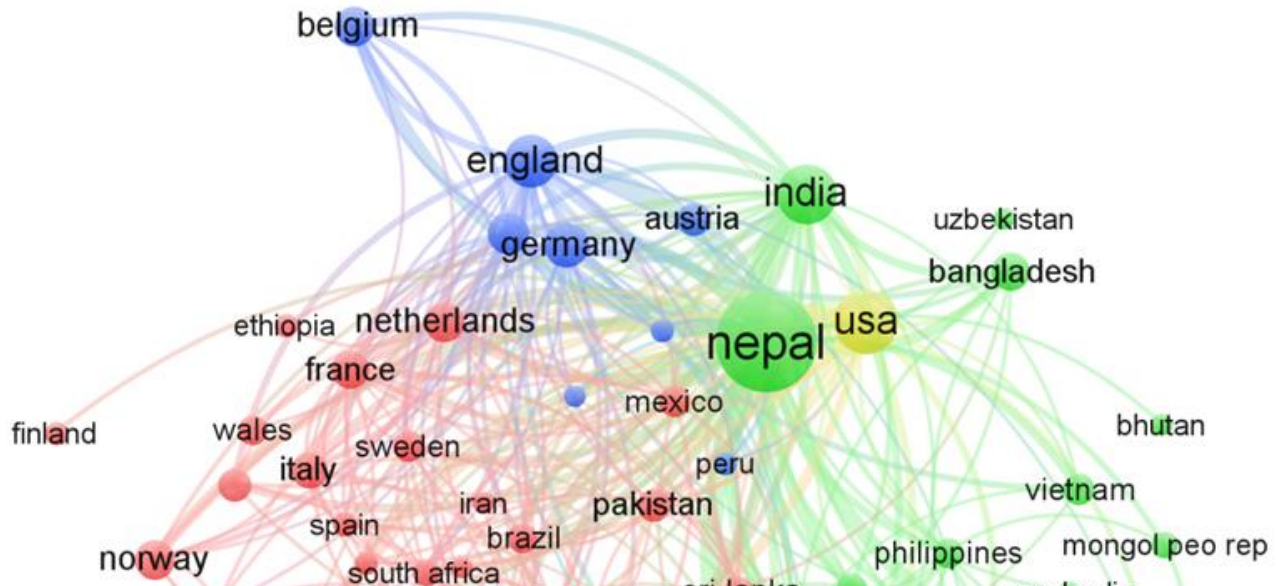

denmark senya sri lanka indonesia cambodia israel nigeria peoples $r$ china

new zealand australia thailand south korea 
Fig. 6

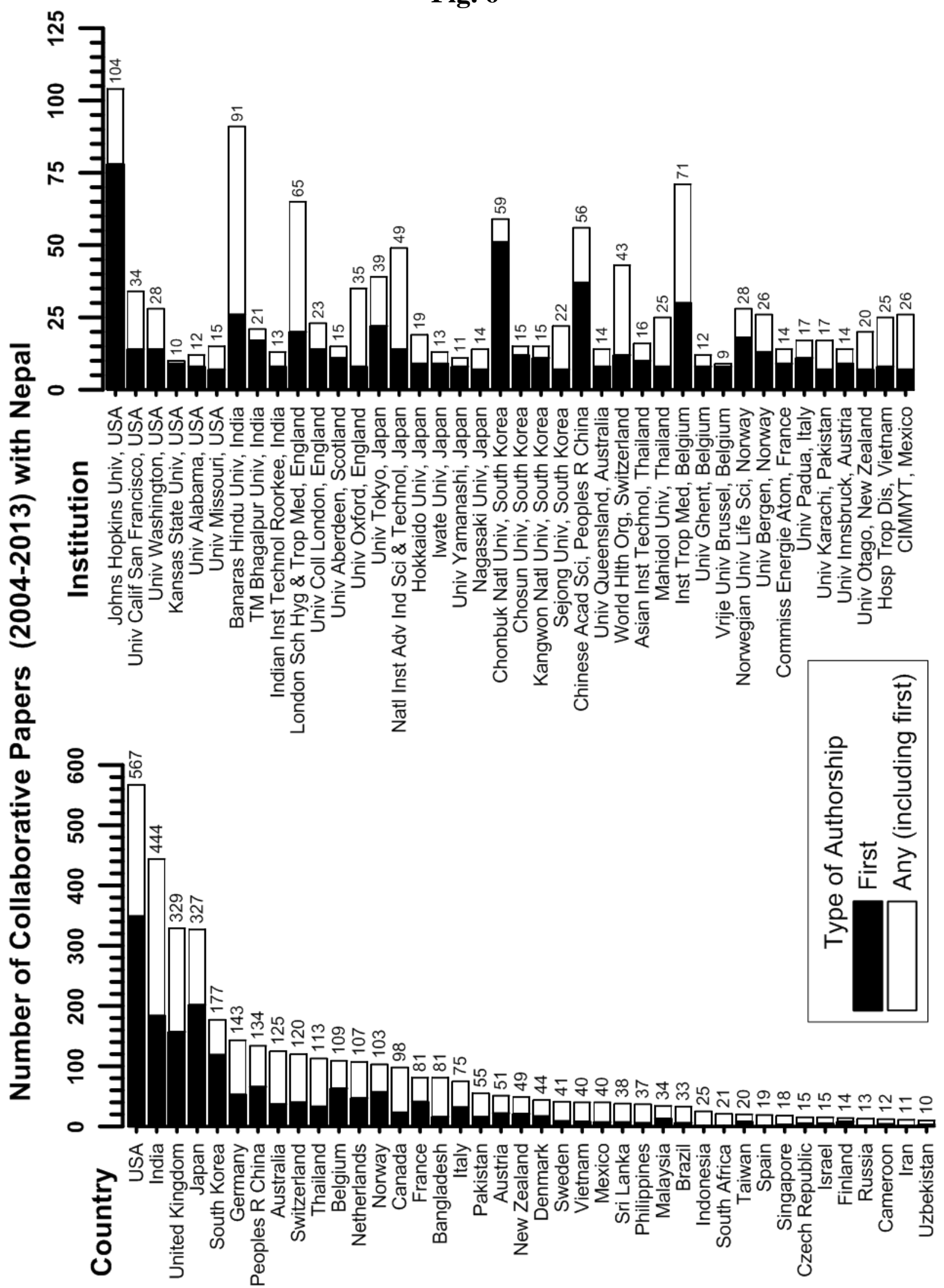


Table 1.

A brief history of establishment of higher education Institutions in Nepal

\begin{tabular}{cl} 
Year & Description \\
\hline 1918 & Tri-Chandra College, the first institute of modern higher education, established \\
1951 & $\begin{array}{l}\text { Advent of democracy paves way for establishment of new public \& community colleges } \\
1959\end{array}$ \\
1965 & $\begin{array}{l}\text { Tribhuvan University, the first university in Nepal, established } \\
5 \text { public and } 51 \text { community colleges with 5,000 and 10,000 enrollments, respectively, } \\
\text { established }\end{array}$ \\
1971 & $\begin{array}{l}\text { Nationalization of all community colleges and linking them with Tribhuvan University } \\
\text { Mahendra Sanskrit University, focused on classical and modern Sanskrit education, } \\
\text { established }\end{array}$ \\
1986 Kathmandu University, a not-for-profit and non-government public university, \\
1993 established \\
1993 Purbanchal University, an autonomous university in Eastern Development Region, \\
$\begin{array}{l}\text { established } \\
\text { BP Koirala Institute of Health Sciences (BPKIHS) established in Eastern Development }\end{array}$ \\
$\begin{array}{l}\text { Region } \\
\text { Pokhara University, an autonomous university in Western Development Region, }\end{array}$ \\
$\begin{array}{l}\text { established } \\
\text { In total, (i) Five accredited universities: Tribhuvan University, Kathmandu University, } \\
\text { Pokhara University, Nepal Sanskrit University and Purbanchal University; (ii) Four newly } \\
\text { proposed but yet to be accredited universities: Lumbini Buddha University, Agriculture } \\
\text { and Forestry University, Mid Western University and Far-western University reporting to } \\
\text { the Ministry of Education and Sports; (iii) Two other institutions, BPKIHS and National } \\
\text { Academy of Medical Sciences, reporting to the Ministry of Health. }\end{array}$
\end{tabular}


Table 2.

Distribution of the WoS core journal publications (2004-2013) from Nepal into 22 disciplinary fields and major bibliometric indicators based on WoS and InCites.

\begin{tabular}{|c|c|c|c|c|c|c|c|}
\hline $\begin{array}{l}\text { S. } \\
\text { No. }\end{array}$ & $\begin{array}{l}\text { Research disciplines } \\
\text { (ESI } 22 \text { fields) }\end{array}$ & $\mathbf{N}_{\text {doc }}$ & $\begin{array}{l}\% \\
\text { Share }\end{array}$ & NTop10 & $\begin{array}{l}\text { PP(Top10) } \\
\%\end{array}$ & $\begin{array}{l}\text { Average } \\
\mathrm{CNCl}\end{array}$ & $\begin{array}{l}\% \text { Int } \\
\text { Co- } \\
\text { auth }\end{array}$ \\
\hline 1 & Agricultural Sciences & 137 & $4.5 \%$ & 14 & $10.2 \%$ & 0.93 & $91.2 \%$ \\
\hline 2 & $\begin{array}{l}\text { Biology \& } \\
\text { Biochemistry }\end{array}$ & 64 & $2.1 \%$ & 10 & $15.6 \%$ & 1.07 & $95.3 \%$ \\
\hline 3 & Chemistry & 116 & $3.9 \%$ & 11 & $9.5 \%$ & 0.86 & $94.8 \%$ \\
\hline 4 & Clinical Medicine & 1189 & $39.5 \%$ & 80 & $6.7 \%$ & 1.27 & $56.5 \%$ \\
\hline 5 & Computer Science & 7 & $0.2 \%$ & 1 & $14.3 \%$ & 0.96 & $85.7 \%$ \\
\hline 6 & $\begin{array}{l}\text { Economics \& } \\
\text { Business }\end{array}$ & 21 & $0.7 \%$ & 5 & $23.8 \%$ & 1.47 & $90.4 \%$ \\
\hline 7 & Engineering & 67 & $2.2 \%$ & 4 & $6.0 \%$ & 0.71 & $86.5 \%$ \\
\hline 8 & Environment/Ecology & 292 & $9.7 \%$ & 25 & $8.6 \%$ & 0.80 & $83.5 \%$ \\
\hline 9 & Geosciences & 163 & $5.4 \%$ & 36 & $22.1 \%$ & 1.70 & $95.7 \%$ \\
\hline 10 & Immunology & 36 & $1.2 \%$ & 4 & $11.1 \%$ & 0.93 & $94.4 \%$ \\
\hline 11 & Materials Science & 51 & $1.7 \%$ & 6 & $11.8 \%$ & 1.10 & $94.1 \%$ \\
\hline 12 & Mathematics & 11 & $0.4 \%$ & 0 & $0.0 \%$ & 0.21 & $90.9 \%$ \\
\hline 13 & Microbiology & 65 & $2.2 \%$ & 8 & $12.3 \%$ & 0.94 & $83.0 \%$ \\
\hline 14 & $\begin{array}{l}\text { Molecular Biology \& } \\
\text { Genetics }\end{array}$ & 52 & $1.7 \%$ & 13 & $25.0 \%$ & 1.50 & $100.0 \%$ \\
\hline 15 & Multidisciplinary & 20 & $0.7 \%$ & 10 & $50.0 \%$ & 4.06 & $100.0 \%$ \\
\hline 16 & $\begin{array}{l}\text { Neuroscience \& } \\
\text { Behavior }\end{array}$ & 18 & $0.6 \%$ & 0 & $0.0 \%$ & 0.24 & $61.1 \%$ \\
\hline 17 & $\begin{array}{l}\text { Pharmacology \& } \\
\text { Toxicology }\end{array}$ & 53 & $1.8 \%$ & 6 & $11.3 \%$ & 0.95 & $86.7 \%$ \\
\hline 18 & Physics & 61 & $2.0 \%$ & 4 & $6.6 \%$ & 0.51 & $88.5 \%$ \\
\hline 19 & $\begin{array}{l}\text { Plant \& Animal } \\
\text { Science }\end{array}$ & 297 & $9.9 \%$ & 18 & $6.1 \%$ & 0.65 & $83.5 \%$ \\
\hline 20 & Psychiatry/Psychology & 36 & $1.2 \%$ & 5 & $13.9 \%$ & 1.15 & $94.4 \%$ \\
\hline 21 & $\begin{array}{l}\text { Social Sciences, } \\
\text { general }\end{array}$ & 240 & $8.0 \%$ & 16 & $6.7 \%$ & 0.87 & $77.5 \%$ \\
\hline 22 & Space Science & 15 & $0.5 \%$ & 0 & $0.0 \%$ & 0.22 & $100.0 \%$ \\
\hline & Total or Average & 3011 & $100 \%$ & 276 & $9.2 \%$ & 1.08 & $76.4 \%$ \\
\hline
\end{tabular}

Note: Ndoc $=$ No. of documents; $\%$ Share $=$ Share of the discipline relative to the total documents; NTop $10=$ No. of documents corresponding to top 10 percent by citation; $\mathrm{PP}(\mathrm{Top} 10)=\%$ of papers in top $10 \%$ by citation; $\mathrm{CNCl}=$ Category normalized citation impact; Int Coauth = percentage of papers with international co-authorship. WoS data as of 2014/8/11; InCites-based data for impact indicators extracted from the update of 2016/8/19. 
Table 3. Top five foreign countries (collaborating with Nepal) and institutions (both from Nepal and abroad) by research fields covered by 3,011 core journal publications.

\begin{tabular}{|c|c|c|}
\hline $\begin{array}{l}\text { Research } \\
\text { disciplines } \\
\text { (ESI } 22 \text { fields) }\end{array}$ & $\begin{array}{l}\text { Countries (\% documents) of origin } \\
\text { of co-authors (Nepal:100\%) }\end{array}$ & Nepalese and foreign institutions of affiliation of co-authors \\
\hline $\begin{array}{l}\text { Agricultural } \\
\text { Sciences }\end{array}$ & $\begin{array}{l}\text { USA (18.2\%); UK (16\%); India } \\
(15.3 \%) ; \text { Australia (11.6\%); Mexico } \\
(10.2 \%)\end{array}$ & $\begin{array}{l}\text { Ctr Int Mejoramiento Maiz \& Trigo (27.7\%); Tribhuvan Univ (22.6\%); Nepal } \\
\text { Agr Res Council (13.8\%); Johns Hopkins Univ (9.4\%); Kathmandu Univ } \\
(8 \%)\end{array}$ \\
\hline $\begin{array}{l}\text { Biology \& } \\
\text { Biochemistry }\end{array}$ & $\begin{array}{l}\text { South Korea (31.2\%); Japan }(28.1 \%) \text {; } \\
\text { USA }(21.8 \%) \text {; Australia }(14 \%) \text {; India }\end{array}$ & $\begin{array}{l}\text { Tribhuvan Univ (50\%); Res Lab Biotechnol \& Biochem Nepal (18.7\%); } \\
\text { AIST Japan (12.5\%); Chosun Univ (9.3\%); Gwangju Univ (9.3\%) }\end{array}$ \\
\hline
\end{tabular}

Chemistry India (21.5\%); South Korea (19.8\%); USA (15.5\%); Japan (15.5\%); Germany $(12.9 \%)$

Clinical USA (19.2\%); India (14.4\%); UK

Medicine $\quad(12.5 \%)$; Switzerland (5.1\%); Belgium $(4.7 \%)$

Computer $\quad$ South Korea (28.5\%); India (14.2\%);

Science UK (14.2\%); Belgium (14.2\%); Netherlands (14.2\%)

Economics \& USA (33.3\%); UK (33.3\%); Japan

Business $\quad(14.2 \%)$; Netherlands (9.5\%); Italy $(9.5 \%)$

Engineering USA (19.4\%); India (19.4\%); Japan $(14.9 \%)$; UK (10.4\%); South Korea $(8.9 \%)$

Environment/Ec USA (18.8\%); India (13\%); Peoples R ology China (13\%); Japan (12.6\%); UK $(9.5 \%)$

Geosciences USA (24.5\%); Japan (20.2\%); France (18.4\%); India (15.3\%); Germany $(10.4 \%)$

Immunology USA (44.4\%); India (22.2\%); UK (16.6\%); Thailand (16.6\%); Belgium $(16.6 \%)$

Materials $\quad$ South Korea (45\%); Japan (23.5\%); Science India (11.7\%); Mongol Peo Rep (11.7\%); Germany $(9.8 \%)$

Mathematics India (27.2\%); Japan (18.1\%); Brazil $(18.1 \%)$; South Korea $(9 \%)$; Italy $(9 \%)$

Microbiology Japan (23\%); India (18.4\%); USA (15.3\%); UK (15.3\%); South Korea $(13.8 \%)$

Molecular Japan (69.2\%); South Korea (38.4\%); Biology \& $\quad$ USA (36.5\%); India (25\%); Peoples R Genetics $\begin{array}{ll}\text { Multidisciplinary } & \text { India (45\%); USA (40\%); Germany } \\ & (15 \%) \text {; Canada (15\%); France }(15 \%)\end{array}$ Neuroscience \& $\quad$ India (11.1\%); South Korea (11.1\%); Behavior $\quad$ France (11.1\%); Czech Republic France (11.1\%); Czech
(11.1\%); Japan (5.5\%)

Pharmacology Germany (15\%); USA (9.4\%); Japan \& Toxicology $\quad(9.4 \%)$; South Korea $(9.4 \%)$; India $(7.5 \%)$

Physics India (42.6\%); USA (11.4\%); South Korea (11.4\%); Italy (6.5\%); New Zealand $(6.5 \%)$

Plant \& Animal Japan (20.5\%); USA (16.1\%); India Science $\quad(13.8 \%)$; UK $(8.7 \%)$; South Korea $(8.4 \%)$

Psychiatry/Psyc USA (52.7\%); Netherlands (22.2\%); hology UK (16.6\%); Norway (16.6\%); India $(13.8 \%)$

Social USA (21.2\%); UK (15.4\%); India Sciences, $\quad(12 \%)$; Japan $(6.6 \%)$; Thailand $(6.6 \%)$ general Space Science Austria (93.3\%); Germany (13.3\%); New Zealand (6.6\%)

All fields* $\quad$ USA (18.8); India (14.7\%); UK $(10.9 \%)$; Japan $(10.9 \%)$; South Korea (5.9\%); Germany (4.7\%); Peoples R China (4.5\%); Australia (4.2\%); Switzerland (4.0\%); Thailand (3.8\%)
Tribhuvan Univ (68.1\%); Chonbuk Natl Univ (17.2\%); Res Lab Biotechnol \& Biochem Nepal (6.8\%); TM Bhagalpur Univ (6.8\%); Univ Halle Wittenberg $(6.8 \%)$

BP Koirala Inst HIth Sci (24\%); Tribhuvan Univ (18\%); Manipal Coll Med Sci Nepal (6.4\%); Johns Hopkins Univ (5.9\%); Inst Trop Med Antwerp $(4.5 \%)$

Tribhuvan Univ (42.8\%); Chosun Univ (28.5\%); Ctr Ecol \& Hydrol Wallingford (14.2\%); Ghana Adv Program (14.2\%); Gomendra Multiple Coll $(14.2 \%)$

Tribhuvan Univ (52.3\%); Univ E Anglia (14.2\%); UN World Food

Programme (9.5\%); Univ Calif System (9.5\%); Univ Copenhagen (9.5\%)

Tribhuvan Univ (35.8\%); Kathmandu Univ (11.9\%); Int Ctr Integrated Mt Dev (5.9\%); Norwegian Univ Sci \& Technol (4.4\%); Res Lab Biotechnol \& Biochem Nepal (4.4\%)

Int Ctr Integrated Mt Dev (24.3\%); Tribhuvan Univ (19.1\%); Chinese Acad Sci (9.9\%); Kathmandu Univ (8.9\%); World Wildlife Fund (4.7\%)

Tribhuvan Univ (49\%); Int Ctr Integrated Mt Dev (11\%); Natl Seismol Ctr Nepal (9.8\%); Chinese Acad Sci (7.9\%); Kathmandu Univ (7.3\%)

Tribhuvan Univ (27.7\%); BP Koirala Inst Hlth Sci (19.4\%); Inst Trop Med Antwerp (16.6\%); Anandaban Hosp (13.8\%); Banaras Hindu Univ (8.3\%)

Tribhuvan Univ (78.4\%); Chonbuk Natl Univ (39.2\%); Mongolian Univ Sci \& Technol (11.7\%); Univ Halle Wittenberg (9.8\%); Nepal Acad Sci \& Technol $(7.8 \%)$

Tribhuvan Univ (72.7\%); Kathmandu Univ (27.2\%); Meijo Univ (18.1\%); Indian Inst Technol Roorkee (9\%); Inst Matemat UFRJ (9\%) Tribhuvan Univ (21.5\%); BP Koirala Inst Hlth Sci (18.4\%); Inst Trop Med Antwerp (12.3\%); Kathmandu Univ (12.3\%); Univ Antwerp (12.3\%)

Res Lab Biotechnol \& Biochem Nepal (65.3\%); AIST Japan (34.6\%); Showa Univ (26.9\%); Univ Missouri (17.3\%); Univ Tsukuba (17.3\%)

Int Ctr Integrated Mt Dev (25\%); Tribhuvan Univ (20\%); Indian Inst Sci (15\%); Univ Colorado (15\%); Calif State Univ (10\%) BP Koirala Inst HIth Sci (22.2\%); Acad Sci Czech Republic (11.1\%); Coll Med Sci \& Teaching Hosp Bharatpur (11.1\%); Kathmandu Univ (11.1\%); Natl Inst Neurol \& Allied Sci Kathmandu (11.1\%)

Tribhuvan Univ (43.3\%); Pokhara Univ (13.2\%); Manipal Coll Med Sci Nepal (9.4\%); Univ Bielefeld (7.5\%); Mahidol Univ (5.6\%)

Tribhuvan Univ (77\%); TM Bhagalpur Univ (18\%); Mizoram Univ (11.4\%); Nepal Acad Sci \& Technol (11.4\%); Kathmandu Univ (8.1\%)

Tribhuvan Univ (39.7\%); Ctr Int Mejoramiento Maiz \& Trigo (13.4\%); Nepal Agr Res Council (10.4\%); Kathmandu Univ (5.7\%); Gifu Univ (5.3\%)

Tribhuvan Univ (33.3\%); Transcultural Psychosocial Org Nepal (19.4\%); Univ Oslo (19.4\%); Healthnet TPO Amsterdam (16.6\%); Univ Calif System $(16.6 \%)$

Tribhuvan Univ (21.2\%); BP Koirala Inst HIth Sci (6.6\%); Manipal Coll Med Sci Nepal (5.8\%); Johns Hopkins Univ (5\%); Univ Tokyo (4.1\%)

Tribhuvan Univ (100\%); Univ Innsbruck (93.3\%); Univ Cologne (13.3\%); Univ Canterbury (6.6\%)

Tribhuvan Univ (29.1\%); BP Koirala Inst Hlth Sci (11.1\%); Kathmandu Univ (5.1\%); Int Ctr Integrated Mt Dev (3.9\%); Johns Hopkins Univ (3.5\%); Manipal Coll Med Sci Nepal (3.3\%); Banaras Hindu Univ (3.0\%); Ctr Int Mejoramiento Maiz \& Trigo (CIMMYT) (2.6\%); Inst Trop Med Antwerp (2.4\%); Res Lab Biotechnol \& Biochem Nepal $(2.4 \%)$ 
Table 4 Comparison of the prolific fields (> 4\% share) in the $2006-2010$ publications indexed in Scopus and WoS.

\begin{tabular}{lll}
\hline Prolific & Scopus ASJC subject area(s) (Ndoc, share & WoS ESI field(s) (Ndoc, share \\
disciplinary & $\%)$ & $\%)$ \\
groups & (Gupta \& Bala 2013) & (This study)
\end{tabular}

\begin{tabular}{|c|c|c|}
\hline $\begin{array}{l}\text { Medical \& } \\
\text { health } \\
\text { sciences }\end{array}$ & $\begin{array}{l}\text { Medicine }(1,878 ; 63.6 \%) \\
\text { Public Health }(37 ; 1.3 \%) \\
\text { Nursing }(60 ; 2.0 \%)\end{array}$ & Clinical Medicine (598; 46.6\%) \\
\hline $\begin{array}{l}\text { Agricultural, } \\
\text { biological and } \\
\text { life sciences }\end{array}$ & $\begin{array}{l}\text { Agricultural \& Biological Sciences (385; } 13.0 \%) \\
\text { Biochemistry, Genetics \& Molecular Biology (223; } \\
7.5 \%) \\
\text { Immunology \& Microbiology }(116 ; 3.9 \%)\end{array}$ & $\begin{array}{l}\text { Plant \& Animal Science }(134 ; 10.4 \%) \\
\text { Agricultural Sciences }(74 ; 5.8 \%) \\
\text { Biology \& Biochemistry }(29 ; 2.3 \%) \\
\text { Molecular Biology \& Genetics }(29 ; \\
2.3 \%) \\
\text { Microbiology }(29 ; 2.3 \%) \\
\text { Immunology }(18 ; 1.4 \%)\end{array}$ \\
\hline $\begin{array}{l}\text { Environmental } \\
\text { sciences }\end{array}$ & Environmental Science $(271 ; 9.2 \%)$ & Environment/Ecology (132; 10.3\%) \\
\hline $\begin{array}{l}\text { Earth and } \\
\text { space } \\
\text { sciences }\end{array}$ & Earth \& Planetary Sciences (123; 4.2\%) & $\begin{array}{l}\text { Geosciences }(61 ; 4.8 \%) \\
\text { Space Science }(11,0.9 \%)\end{array}$ \\
\hline $\begin{array}{l}\text { Engineering } \\
\text { and chemical } \\
\text { sciences }\end{array}$ & $\begin{array}{l}\text { Engineering }(88,3.0 \%) \\
\text { Chemical Engineering }(25 ; 0.8 \%) \\
\text { Chemistry }(74,2.5 \%)\end{array}$ & $\begin{array}{l}\text { Engineering }(34 ; 2.6 \%) \\
\text { Chemistry }(34 ; 2.6 \%)\end{array}$ \\
\hline
\end{tabular}

Note: Due to the differences in the document-discipline assignment by schemes (one document to one WoS ESI field, but one document to one or more Scopus ASJC subject areas), and the number of documents used by each study, the Scopus ASJC numbers are expected to be 2.25 times higher than those in WoS ESI even for identical area/fields. Details given in the text. 
Table 5. Growth in the number of medical doctors in Nepal with time (adapted from Adhikary (2013).

1

2

3

4

5

\begin{tabular}{rrrr}
\hline Reference Year & Cumulative Number & Population & Doctor to population ratio \\
\hline 1961 & 67 & $9,412,996$ & $1: 1,40,492$ \\
1971 & 286 & $11,555,983$ & $1: 40,405$ \\
1981 & 685 & $15,022,839$ & $1: 21,931$ \\
1991 & 1,576 & $18,491,097$ & $1: 11,733$ \\
2001 & 3,530 & $23,151,423$ & $1: 7,558$ \\
2011 & 10,619 & $26,494,504$ & $1: 2,495$ \\
\hline
\end{tabular}

Note: The term "Doctor" refers to any person holding at least a MBBS or its equivalent degree from a Nepalese or foreign university, and registered in Nepal Medical Council. 